\title{
Tissue- and Cell-Specific Cytokinin Activity in Populus $x$ canescens Monitored by ARR5::GUS Reporter Lines in Summer and Winter
}

\author{
Shanty Paul ${ }^{1}$, Henning Wildhagen ${ }^{1}$, Dennis Janz ${ }^{1}$, Thomas Teichmann ${ }^{1 \dagger}$, Robert Hänsch ${ }^{2}$ \\ and Andrea Polle ${ }^{1 *}$ \\ ${ }^{1}$ Department of Forest Botany and Tree Physiology, Georg-August-Universität Göttingen, Göttingen, Germany, ${ }^{2}$ Department \\ of Molecular and Cell Biology of Plants, Institute for Plant Biology, University of Technology, Braunschweig, Germany
}

\section{OPEN ACCESS}

Edited by:

Alison Kingston-Smith,

Aberystwyth University, UK

Reviewed by:

Amarendra Narayan Misra, Central University of Jharkhand, India

Richard Napier,

University of Warwick, UK

*Correspondence: Andrea Polle

apolle@gwdg.de

tPresent address:

Thomas Teichmann, Department of Plant Cell Biology, Albrecht-von-Haller-Institute of Plant Sciences, Georg-August-Universität

Göttingen, Göttingen, Germany

Specialty section:

This article was submitted to Agroecology and Land Use Systems, a section of the journal Frontiers in Plant Science

Received: 03 November 2015 Accepted: 28 April 2016 Published: 13 May 2016

Citation:

Paul S, Wildhagen $H$, Janz $D$, Teichmann T, Hänsch R and Polle $A$ (2016) Tissue- and Cell-Specific Cytokinin Activity in Populus $\times$ canescens Monitored by ARR5:::GUS Reporter Lines in Summer and Winter.

Front. Plant Sci. 7:652. doi: 10.3389/fpls.2016.00652
Cytokinins play an important role in vascular development. But knowledge on the cellular localization of this growth hormone in the stem and other organs of woody plants is lacking. The main focus of this study was to investigate the occurrence and cellular localization of active cytokinins in leaves, roots, and along the stem of Populus $\times$ canescens and to find out how the pattern is changed between summer and winter. An ARR5::GUS reporter construct was used to monitor distribution of active cytokinins in different tissues of transgenic poplar lines. Three transgenic lines tested under outdoor conditions showed no influence of ARR5::GUS reporter construct on the growth performance compared with the wild-type, but one line lost the reporter activity. ARR5::GUS activity indicated changes in the tissue- and cell type-specific pattern of cytokinin activity during dormancy compared with the growth phase. ARR5::GUS activity, which was present in the root tips in the growing season, disappeared in winter. In the stem apex ground tissue, ARR5::GUS activity was higher in winter than in summer. Immature leaves from tissue-culture grown plants showed inducible ARR5::GUS activity. Leaf primordia in summer showed ARR5::GUS activity, but not the expanded leaves of outdoor plants or leaf primordia in winter. In stem cross sections, the most prominent ARR5::GUS activity was detected in the cortex region and in the rays of bark in summer and in winter. In the cambial zone the ARR5::GUS activity was more pronounced in the dormant than in growth phase. The pith and the ray cells adjacent to the vessels also displayed ARR5::GUS activity. In silico analyses of the tissue-specific expression patterns of the whole PtRR type-A family of poplar showed that PtRR10, the closest ortholog to the Arabidopsis ARR5 gene, was usually the most highly expressed gene in all tissues. In conclusion, gene expression and tissue-localization indicate high activity of cytokinins not only in summer, but also in winter. The presence of the signal in meristematic tissues supports their role in meristem maintenance. The reporter lines will be useful to study the involvement of cytokinins in acclimation of poplar growth to stress.

Keywords: cytokinin, localization, ARR5, summer, winter, dormancy, wood 


\section{INTRODUCTION}

Cytokinins are adenine derivatives that act as master regulators of plant growth and development. They are synthesized mainly in the root tips (Dieleman et al., 1997; Miyawaki et al., 2004; Aloni et al., 2005), but also locally in shoot tissues (Sakakibara, 2006; Tanaka et al., 2006; Hirose et al., 2008; Kamada-Nobusada and Sakakibara, 2009). Root-derived cytokinins are transported acropetally through xylem sap by the transpirational pull (Aloni et al., 2005), while shoot-derived cytokinins are transported through phloem (Bishopp et al., 2011). Active and inactive forms of cytokinins occur as free bases and as ribosides, ribotides, or glucose conjugates, respectively (Mok and Mok, 2001; Romanov et al., 2006).

Cytokinins have roles in almost all aspects of plant growth and development including cell division, shoot initiation and growth, sink/source relationships, nutrient uptake, breaking of bud dormancy, delay of leaf senescence, and regulation of vascular development (Hwang et al., 2012; Kieber and Schaller, 2014). Cytokinins determine vascular cell identities, except those of the protoxylem (Mähönen et al., 2000; Hutchison et al., 2006; Yokoyama et al., 2007; Argyros et al., 2008) and promote the development of vascular cambium (Matsumoto-Kitano et al., 2008; Nieminen et al., 2008). Cytokinins specify the vascular pattern by regulating the level of PIN auxin efflux proteins (Bishopp et al., 2011). Cytokinins increase the sensitivity of the cambium to the auxin signal thereby determining wood quantity and quality (Aloni, 1991, 2001).

Cytokinin perception and signaling in plants has been extensively studied in Arabidopsis and involves a His-Asp phosphorelay that mediates the signal transmission (Mizuno, 2005; Schaller et al., 2008). Among the response regulators in this pathway, type-A ARRs (Arabidopsis Response Regulators), i.e., genes which contain the highly conserved Lys and two Asp residues in their receiver domains, are the primary response genes for cytokinins (D'Agostino et al., 2000). Ten type-A ARR genes are described in Arabidopsis (D'Agostino et al., 2000; Schaller et al., 2008; Pils and Heyl, 2009) and eleven in Populus trichocarpa (Ramírez-Carvajal et al., 2008; Immanen et al., 2013). The ARR genes are transcriptionally regulated and can be induced by exogenous cytokinin treatment (D'Agostino et al., 2000; Taniguchi et al., 1998).

In trees, changes in endogenous cytokinin levels in relation to seasonality have been studied for a long time. Most of these studies focused on the endogenous cytokinin levels in xylem or phloem sap of the trees (Hewett and Wareing, 1973; Alvim et al., 1976; Weiler and Ziegler, 1981; Tromp and Ovaa, 1990; Cook et al., 2001) or reported the endogenous cytokinin concentrations in different organs (Hewett and Wareing, 1973; Van Staden and Dimalla, 1981; Cook et al., 2001). Furthermore active and inactive forms of cytokinins were distinguished (Hewett and Wareing, 1973; Van Staden and Dimalla, 1981; Tromp and Ovaa, 1990) and their changes were related to seasonal fluctuations (Tromp and Ovaa, 1990). For example, in the xylem sap of apple trees, the active trans-zeatin type (tZ) levels were high during the growing season, dropped during dormancy and showed an increase during bud burst, whereas continued to increase during the growing season (Tromp and Ovaa, 1990). Despite the importance of cytokinins in vascular development, knowledge on the cellular localization of this growth hormone in the stem and other organs of woody plants is still lacking. Furthermore, it is unclear how the tissue-specific distribution of active cytokinins is influenced by dormancy.

The goal of this study was to investigate the occurrence and cellular localization of active cytokinins in leaves, roots and along the stem of poplar and to find out how the pattern is changed between the active growth phase in summer and dormancy in winter. Our hypothesis was that cytokinin activity was present in actively growing tissues in summer and lacking in winter, except in those tissues, where cells have to be kept in the meristematic stage. Tissue-specific localization patterns of cytokinin activity were also compared with expression of genes belonging to the type-A Response Regulator (RR) family in poplar. In Arabidopsis, the ARR5::GUS ( $\beta$-glucuronidase) reporter construct has been used to monitor the distribution of active cytokinins in different tissues (D'Agostino et al., 2000). ARR5 has high homology to the cytokinin-inducible gene PtRR10 of Populus trichocarpa (Ramírez-Carvajal et al., 2008; Immanen et al., 2013). Here, we employed the ARR5::GUS construct as a tool to investigate the localization pattern of active cytokinins in poplar. The transgenic poplar cytokinin reporter lines were grown outdoors under ambient conditions and used to map ARR5 activity in summer and winter.

\section{MATERIALS AND METHODS}

\section{Plant Transformation}

The ARR5::GUS construct described in D'Agostino et al. (2000) was provided by Prof. Kieber (University of North Carolina, Chapel Hill, NC, USA), cloned, transformed into Agrobacterium tumefaciens strain C58C1/MP90 and then used to transform Populus $\times$ canescens [INRA (Institut National de la Recherche Agronomique) clone 717-1B4] as described by Teichmann et al. (2008). Plantlets were regenerated, maintained on Murashige and Skoog (MS) medium containing $50 \mathrm{mg} \mathrm{l}^{-1}$ kanamycin and micropropagated after Leple et al. (1992).

\section{Selection of Transgenic Reporter Lines}

Leaves from 3-week-old transformed plantlets were collected and GUS staining was performed according to Jefferson et al. (1987) as modified by Teichmann et al. (2008). Briefly, the presence of GUS activity was investigated in intact leaves that were vacuum-infiltrated with GUS buffer $\left(100 \mathrm{mM} \mathrm{NaH} \mathrm{PO}_{4}\right.$, pH 7.0, $10 \mathrm{mM} \mathrm{Na} \mathrm{E}_{4} \mathrm{EDTA}, 0.05 \%$ Triton X-100) containing $1 \mathrm{mg} \mathrm{ml}^{-1}$ 5-bromo-4-chloro-3-indolyl- $\beta$-D-glucuronic acid (Duchefa, Haarlem, The Netherlands). The leaves were then incubated in the dark at $37^{\circ} \mathrm{C}$ for $24 \mathrm{~h}$ and chlorophyll was removed by ethanol treatment. The ARR5::GUS activity was observed mainly in the petiole and primary veins of these leaves. The leaves were viewed and photographed directly. From the regenerated plantlets which were maintained on MS medium containing kanamycin, 17 lines showed GUS activity after GUS staining, mainly in the veins (Figures 1A,B). 


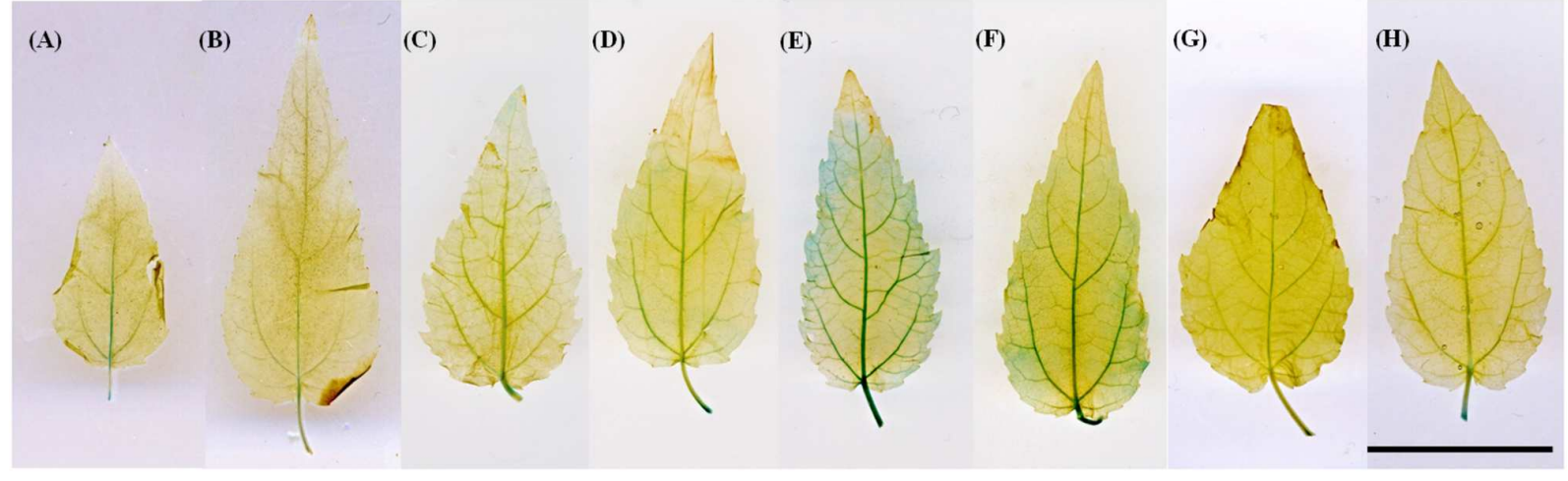

FIGURE 1 | ARR5::GUS activity in leaves of ARR5::GUS poplar reporter line. The leaves of line 80 were incubated directly in GUS staining solution (A,B) or GUS staining was performed after mock-incubated in $0.1 \%$ DMSO (solvent control; C,D). (E,F) show ARR5::GUS activity in leaves after petiole-feeding with $5 \mu \mathrm{M}$ thidiazuron and BAP, respectively, while (G,H) show ARR5::GUS activity in leaves after petiole feeding with $5 \mu \mathrm{M}$ adenine in the light $\left(200 \mu \mathrm{mol}\right.$ quanta $\mathrm{m}^{-2} \mathrm{~s}^{-1}$ PAR) for $24 \mathrm{~h}$. Scale bar $=2 \mathrm{~cm}$

The pattern was similar to that of mock treated leaves (Figures 1C,D).

All plantlets from these 17 lines showed similar morphology and growth in vitro when compared to the wild-type (WT). Plantlets from each line were propagated in vitro. The leaves from these lines were also treated with an exogenous cytokinin supply in order to monitor the response of ARR5::GUS construct to cytokinin. For this purpose, leaves from 3-week-old in vitro micropropagated plantlets were fed by the petioles with a solution containing $5 \mu \mathrm{M}$ thidiazuron (Duchefa, Haarlem, The Netherlands) or $5 \mu \mathrm{M}$ 6-benzylaminopurine (BAP, SigmaAldrich Chemie, Steinheim, Germany) in 0.1\% DMSO (Merck KGaA, Darmstadt, Germany), both active cytokinin analogs or $5 \mu \mathrm{M}$ adenine (Sigma-Aldrich Chemie, Steinheim, Germany), which is an inactive cytokinin analog. A solution of $0.1 \% \mathrm{DMSO}$ (Merck KGaA, Darmstadt, Germany) was used as the solvent control. During the treatment the leaves were kept inside a sealed glass jar at high humidity to avoid desiccation stress. The leaves were allowed to transpire under $200 \mu \mathrm{mol}$ quanta $\mathrm{m}^{-2} \mathrm{~s}^{-1}$ photosynthetically active radiation (PAR) for $24 \mathrm{~h}$. Afterward, the leaves were directly used for GUS staining as above. Examples for cytokinin induction of the ARR5 promoter in thidiazuronor BAP-fed leaves are shown in Figures 1E,F. When compared to controls, the thidiazuron-treated leaves showed a strong induction in ARR5::GUS activity over the leaf blade and in tertiary veins (Figure 1E). On the other hand, the leaves treated with the inactive cytokinin analog adenine did not show an induction (Figures 1G,H). For documentation of staining pattern, the leaves were laid flat in a petri dish filled with distilled water and were scanned (Canoscan 4400F, Canon Inc., China).

From the lines that showed an increased ARR5::GUS activity under exogenous cytokinin treatment, three lines (line 9, 32, and 80) were selected for the study.

\section{Plant Cultivation}

In vitro micropropagated plantlets of the lines 9, 32, and 80 along with WT, were grown in hydroponics for 3 weeks and then transferred into pots with soil (Fruhstorfer Erde Type N, Hawite Gruppe GmbH, Vechta, Germany) as described by Müller et al. (2013). The plants were grown in a greenhouse for 3 months under controlled environmental conditions: $16 \mathrm{~h}$ day length, $200 \mu \mathrm{mol}$ quanta $\mathrm{m}^{-2} \mathrm{~s}^{-1} \mathrm{PAR}, 20^{\circ} \mathrm{C}$ air temperature and $55 \%$ relative air humidity. Afterward, the potted plants were transferred from the greenhouse to a caged area outdoors (Göttingen, Germany, 51.55739 ${ }^{\circ} \mathrm{N}, 9.95857^{\circ} \mathrm{E}, 293 \mathrm{~m}$ above sea level) and acclimated to ambient light and temperature (after Müller et al., 2013). On 18th July 2011, the poplars were planted in four boxes $(3.5 \mathrm{~m}$ length $\times 3 \mathrm{~m}$ width $\times 0.7 \mathrm{~m}$ height $)$ filled with a compost soil and sand mixture (1:1) (Vogteier Erdenwerk $\mathrm{GmbH}$, Niederdorla, Germany). The WT and transgenic lines were planted in a mixed design. Each box was equipped with a total of 42 plants comprising 10 plants each of WT, line 9 and 80 , and 12 plants of line 32 . The first row of plants near to the box edges was not included in any of the analyses to avoid edge effects.

During the growing season, plants were watered with tap water every second day or daily on warm days. Air temperature, relative humidity, and PAR for every hour per day were recorded during the whole study period using MeteoLOG TDL 14 data logger (Adolf Thies GmbH \& Co. KG, Göttingen, Germany).

\section{Harvest}

Harvests were conducted in the growing season (August, 2012) when the mean temperature was $22.4^{\circ} \mathrm{C}$ and during dormancy (January, 2013) when the mean temperature was $-5.0^{\circ} \mathrm{C}$. In the growing season harvest, four plants each from WT, line 9, 32, and 80 were harvested. In the dormancy harvest, one plant from WT and two plants from each line 9, 32, and 80 were harvested. Roots, bark, wood, and leaves were separated and fresh mass was determined for each fraction. Aliquots of these plant tissues were oven dried at $60^{\circ} \mathrm{C}$ for 7 days for measurement of dry mass. Tissue dry mass ( $\mathrm{g}$ ) was calculated as:

$\frac{\text { Dry mass of the aliquot }(\mathrm{g}) \times \text { total tissue fresh mass }(\mathrm{g})}{\text { fresh mass of the aliquot }(\mathrm{g})}$


During harvest, the following fresh tissues were collected for GUS staining: one half of the apical bud, leaf disks (diameter $5 \mathrm{~mm}$ ) from the first fully developed leaf from the apex, stem cross sections ( $2 \mathrm{~mm}$ thickness) at three positions: top (50 $\mathrm{mm}$ beneath the stem apex), middle (the position in the stem exactly in the center between the apex and the shoot-root junction) and bottom (50 $\mathrm{mm}$ above the root-shoot junction), and fine root tips. The stem cross sections were cut using a micro-saw (Proxxon, Föhren, Germany). The materials were directly transferred into the GUS buffer and GUS staining was performed as described above.

\section{GUS Activity Analyses at Tissue and Cellular Level}

Tissue staining patterns were documented by photos, which were taken with a digital camera (DFC420 C, Leica Microsystems Ltd., Germany) attached to a stereomicroscope (M205 FA, Leica Microsystems Ltd., Wetzlar, Germany). The stained tissues were fixed in a solution of 1 part of $37 \%$ formaldehyde, 1 part of $100 \%$ acetic acid, and 18 parts of $70 \%$ ethanol. Subsequently, the fixed tissues were dehydrated in a series of ethanol solutions $(70,80,90$, and $96 \%(\mathrm{v} / \mathrm{v}))$ for $2 \mathrm{~h}$ each at room temperature. The tissues were embedded in Technovit 7100 resin (Heraeus Kulzer GmbH \& Co. KG, Germany) according to manufacturer's instructions with the following modifications: The dehydrated samples were infiltrated in 1:1 (v/v) solutions of $96 \%$ ethanol and Technovit 7100 basic solution for $5 \mathrm{~h}$. Then the samples were infiltrated in 1:2 and then in $1: 3(\mathrm{v} / \mathrm{v})$ solutions of $96 \%$ ethanol and Technovit 7100 basic solution for 12 and $5 \mathrm{~h}$, respectively. Thereafter, the samples were treated with Technovit 7100 infiltration medium consisting of $1 \mathrm{~g}$ Hardner I in $100 \mathrm{ml}$ Technovit 7100 basic solution (provided by the manufacturer) for $24 \mathrm{~h}$. A reduced pressure of $20 \mathrm{kPa}$ for $15 \mathrm{~min}$ was applied at each step during infiltration. Finally, the tissues were embedded in the embedding medium (prepared by mixing $30 \mathrm{ml}$ infiltration medium and $1.5 \mathrm{ml}$ Hardner II provided by the manufacturer). Sections of $15 \mu \mathrm{m}$ thickness were cut with a rotarymicrotome (RM 2265, Leica Microsystems, Wetzlar, Germany) and viewed under a microscope (Axioplan Observer.Z1, Carl Zeiss GmbH, Germany). Photographs were taken at $100 \times$ and $200 \times$ magnification with a digital camera (Axio Cam MRC, Carl Zeiss Microimaging GmbH, Göttingen, Germany) attached to the microscope (Axioplan Observer.Z1, Carl Zeiss GmbH, Germany).

\section{Gene Expression Analyses of PtRR Type-A Family}

For the analysis of tissue specific expression patterns of poplar genes belonging to the two component RR type-A gene family of cytokinin signaling pathway, the gene list as reported by Ramírez-Carvajal et al. (2008) was used. The genomic sequence of each gene was obtained from Joint Genome Institute, $\mathrm{JGI}^{1}$ and the respective gene IDs were obtained by blasting the genomic sequences in Phytozome v10.1 (Goodstein et al., 2012). The homolog of each gene in Arabidopsis was obtained by blasting

${ }^{1}$ http://genome.jgi-psf.org/Poptr1_1/Poptr1_1.home.html

${ }^{2}$ http://phytozome.jgi.doe.gov/pz/portal.html the protein sequence taken from Phytozome, in TAIR ${ }^{3}$. The gene names and gene IDs of the genes used for the expression analyses have been compiled in Table 1. Microarrays were downloaded from the EMBL-EBI ArrayExpress database (Kolesnikov et al., 2015). For P. × canescens: E-GEOD-16495 (shoot apex; Yordanov et al., 2014), E-MEXP-1928 (mature leaves; Janz et al., 2010), E-MEXP-2120 (mature leaves), E-MEXP-3741(bark; He et al., 2013), E-MEXP-2031 (developing xylem; Janz et al., 2012), E-GEOD-33977 (rays- summer and winter; Larisch et al., 2012), E-MEXP-1874 (fine roots; Luo et al., 2009), E-GEOD-43162 (fine roots; Wei et al., 2013), and for P. trichocarpa: E-GEOD-30507 (stem, shoot and leaf primordia, mature leaves, developing xylem, cambium, bark; Ko et al., 2012), E-MEXP-3910 (young leaves; Bai et al., 2013), E-GEOD-49983 (bark), E-MTAB-1483 (developing xylem and elongation zone; Euring et al., 2014), E-GEOD-21480 (stem- summer and winter); E-MEXP-3909 (young roots; Bai et al., 2013).

For the annotation of the microarray ID to the best gene model, the annotation file downloaded from Aspen Database (Tsai et al., 2011) was used.

\section{Statistical Analyses}

Statistical analyses were performed using the free statistical software R (version 3.1.1, R Core Team, 2014). One-way ANOVA was conducted for dry biomass data with plant lines (transgenic reporter lines and WT) as factor. Normality and homogeneity of variance were tested visually by plotting residuals and the data was transformed logarithmically $\left(\log _{2}\right)$ if needed. Data shown are mean \pm SE. Means were considered to be significantly different with a $p$-value $\leq 0.05$.

For the analyses of expression data, to summarize and normalize the array probes, 'rma' function from the $\mathrm{R}$ package 'affy' (Gautier et al., 2004) obtained from Bioconductor (Kauffmann et al., 2009) was used. Mean transcript abundance of the biological replicates was calculated for each gene in each

${ }^{3}$ www.arabidopsis.org

TABLE 1 | Poplar genes belonging to the two component type-A response regulator gene family (Ramírez-Carvajal et al., 2008) that were used for analysis of tissue-specific expression pattern.

\begin{tabular}{lccc}
\hline $\begin{array}{l}\text { Populus } \\
\text { trichocarpa } \\
\text { gene name }\end{array}$ & $\begin{array}{c}\text { Populus } \\
\text { trichocarpa } \\
\text { gene ID }\end{array}$ & $\begin{array}{c}\text { Arabidopsis } \\
\text { gene name }\end{array}$ & AGI \\
\hline PtRR1 & Potri.010G037800 & ARR3 & AT1G59940 \\
PtRR2 & Potri.008G193000 & ARR3 & AT1G59940 \\
PtRR3 & Potri.002G082200 & ARR9 & AT3G57040 \\
PtRR4 & Potri.003G197500 & ARR9/ARR8 & AT3G57040/ \\
& Potri.001G027000 & ARR9/ARR8 & AT3G57040/ \\
PtRR5 & Potri.006G041100 & ARR9 & AT2G41310 \\
PtRR6 & Potri.016G038000 & ARR8 & AT2G41310 \\
PtRR7 & Potri.019G058900 & ARR17 & AT3G56380 \\
PtRR8 & Potri.013G157700 & UCP030365 & AT5G05240 \\
PtRR9 & Potri.015G070000 & ARR5 & AT3G48100 \\
PtRR10 & Potri.019G133600 & ARR17 & AT3G56380 \\
PtRR11 & & &
\end{tabular}


tissue. When more than one probe set was present for one gene, all probe sets were used to calculate the mean value. The means were used for creating a heatmap with the 'heatmap.2' function from the R package 'gplots' (Warnes et al., 2012).

\section{RESULTS}

\section{The ARR5::GUS Reporter Lines Showed No Growth Differences Compared to Wild-type Poplars}

The poplar lines 9, 32, and 80 were grown in ambient conditions, along with WT plants for 1.5 years. The determination of the dry mass did not show any significant difference among the lines (Table 2). There were no apparent visual differences neither in summer nor in winter (Figure 2) suggesting that the transformation with the ARR5::GUS gene construct did not hit any gene that was relevant for growth and that the expression of the construct had no influence on the plant stature.

\section{ARR5::GUS Activity Reports a Tissue- and Cell-type Specific Pattern of Cytokinin Activity in Poplar in the Growth Phase}

The localization pattern of ARR5::GUS activity during growing season was investigated in apical buds, leaf disks, root tips and in stem cross sections at three positions, i.e., top, middle, and bottom. Plants from line 9 did not display a GUS signal in any of the samples from the outdoor grown plants, suggesting that silencing had occurred. Therefore, the pictures of these samples were not considered.

In the growing season, line 32 and 80 exhibited ARR5::GUS activity in all tissues (Figure 3), except in mature leaves (not shown). In the apical buds, the ARR5::GUS activity was localized in the leaf primordia and also in the apical bud base from where the leaf primordia started (Figure 3A). ARR5::GUS was also expressed in root tips (Figure 3E). Higher magnification showed that the staining was concentrated in the root cap region, decreased in the cell division zone and was stronger again at the onset of the cell elongation zone (Figure 4). The signal showed a gradual decrease toward the direction of the shoot (Figure 4).

Examination of cytokinin activity along the stem revealed strong staining in pith in the region of the stem elongation zone, while the signal in the pith disappeared in the stem middle and at the stem bottom, where the pith was compressed by secondary growth (Figures 3B-D). In the stem middle and at the bottom the bark region below the periderm also showed a strong GUS staining (Figures 3C,D).

To investigate the cellular localization pattern of ARR5::GUS activity, stem cross sections were analyzed at a higher magnification. In the elongation zone strong ARR5::GUS activity in the pith was confirmed, but no staining was detected in the cortex or primary xylem (Figure 5A). In the middle

TABLE 2 | Biomass of 1-year-old Populus x canescens wild-type and ARR5::GUS reporter lines in the growing season.

\begin{tabular}{|c|c|c|c|c|}
\hline & WT & Line 9 & Line 32 & Line 80 \\
\hline \multicolumn{5}{|l|}{ Parameter } \\
\hline Stem + branches (g dry wt) & $162.1 \pm 18.1$ & $124.0 \pm 16.2$ & $159.2 \pm 38.2$ & $228.0 \pm 13.8$ \\
\hline Coarse root (g dry wt) & $74.8 \pm 12.3$ & $59.8 \pm 10.6$ & $63.7 \pm 10.1$ & $84.7 \pm 3.3$ \\
\hline Fine root ( $g$ dry $w t)$ & $5.7 \pm 1.0$ & $4.7 \pm 0.6$ & $6.6 \pm 1.3$ & $5.3 \pm 1.0$ \\
\hline Below-ground (g dry wt) & $80.4 \pm 12.4$ & $64.5 \pm 10.8$ & $70.3 \pm 11.2$ & $90.0 \pm 2.3$ \\
\hline
\end{tabular}

One-year-old whole poplar trees were harvested in August, 2012. Data indicate mean \pm SE $(n=4)$. One-way ANOVA conducted for dry mass of the plant lines did not reveal any significant differences $(p>0.05)$.
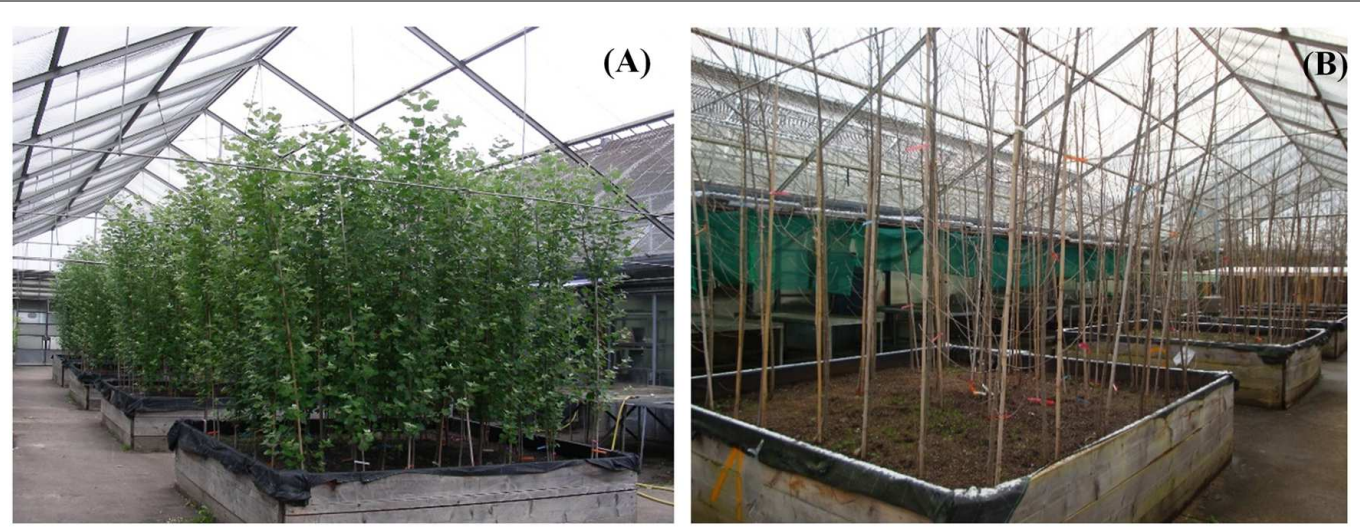

FIGURE 2 | Populus $\times$ canescens wild-type (WT) and ARR5::GUS transgenic reporter lines before harvest in the growth phase (A; August, 2012) and before harvest during dormancy (B; January, 2013). 


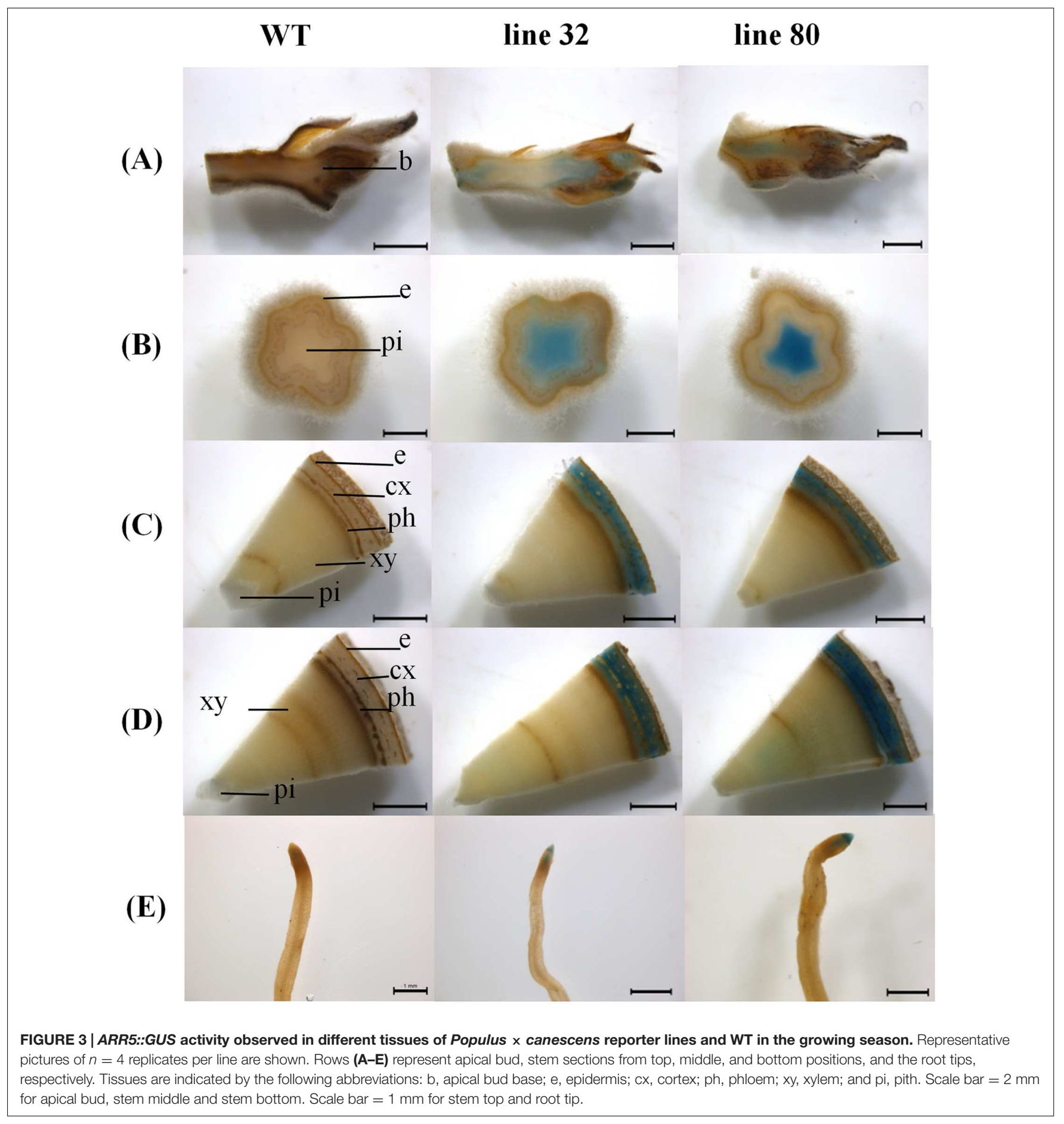

of the stem strong GUS staining was observed only in the cortex between strands of phloem fiber cells (Figure 5B). The stem bottom sections showed a strong staining in the cortex and also in the phloem, especially at the position of the primary rays (Figure 5C). Detailed analysis in the mature xylem showed ARR5::GUS activity in the ray cells adjacent to vessels (Figure 6A). ARR5::GUS activity was also detected in the cambial zone (Figure 6C).

\section{ARR5::GUS Activity Reports Changes in the Tissue- and Cell-type Specific Pattern of Cytokinin Activity during Dormancy Compared with the Growth Phase}

During winter dormancy the apical buds showed no ARR5::GUS activity in the leaf primordia, but a very strong signal in the 


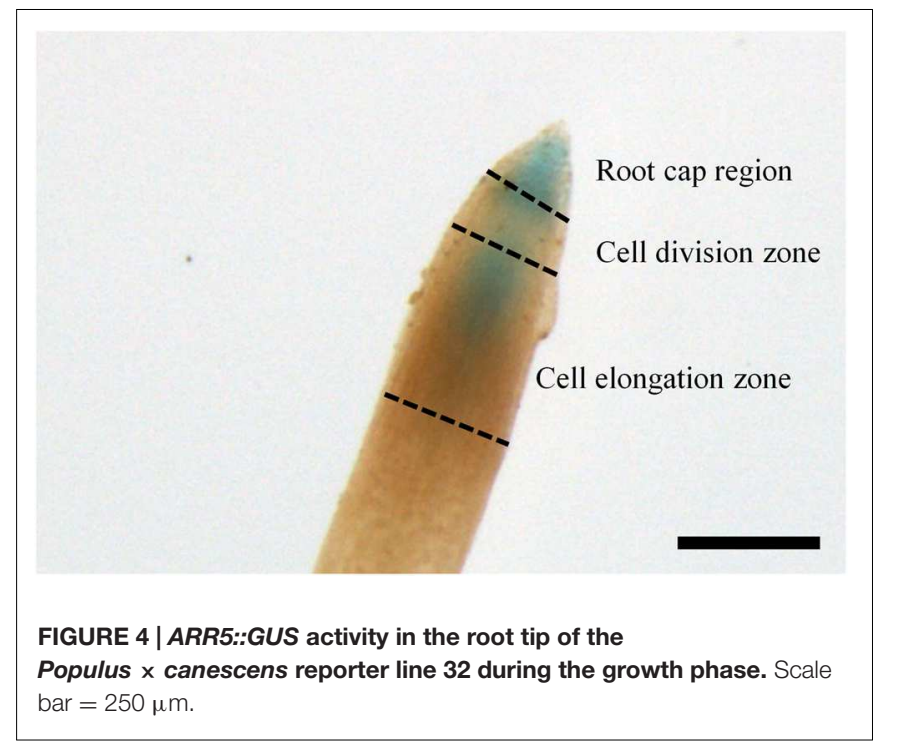

ground tissue below the bud base (Figure 7A). ARR5::GUS activity below the bud base extended into a larger area of the ground tissue of the stem than that observed during the growing season.

Below the apex, at the stem top ARR5::GUS activity was detected in the pith, however, with weaker intensity than in summer (Figure 7B). This signal disappeared in the stem middle and bottom (Figures 7C,D). The stem middle and bottom cross sections showed a strong staining in the bark region (Figures 7C,D). In the root tips ARR5::GUS activity was absent in winter (Figure 7E).

Cellular localization of ARR5::GUS activity was also monitored along the dormant stem (Figure 8). The stem top section, which was collected at the same position below the apex as in summer, showed a fully developed circular ring of secondary xylem, indicating that secondary growth had already started in this zone (Figure 8A). The reason is that after bud set in fall, elongation growth stops and the undifferentiated ground tissues continue to develop for some

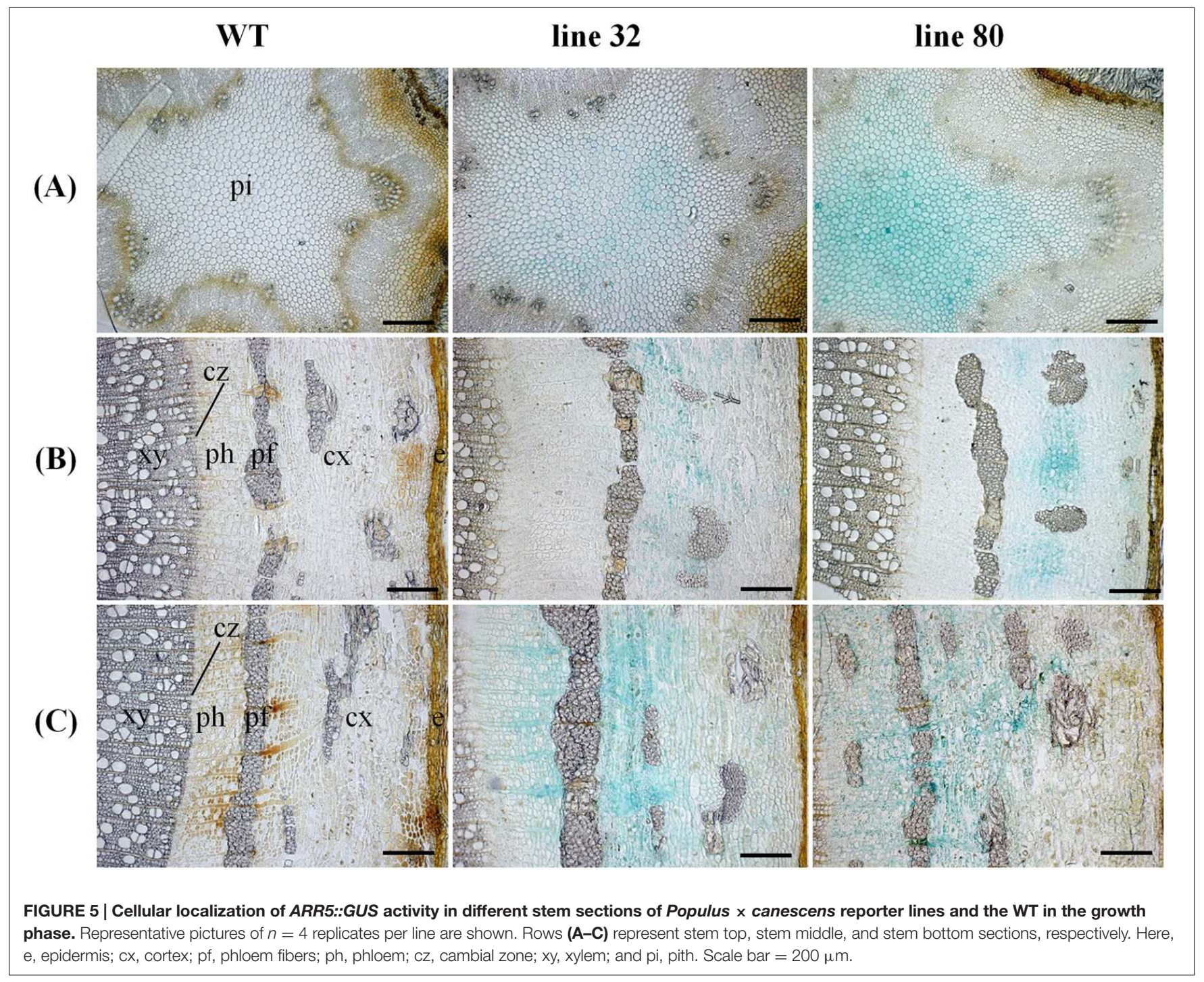




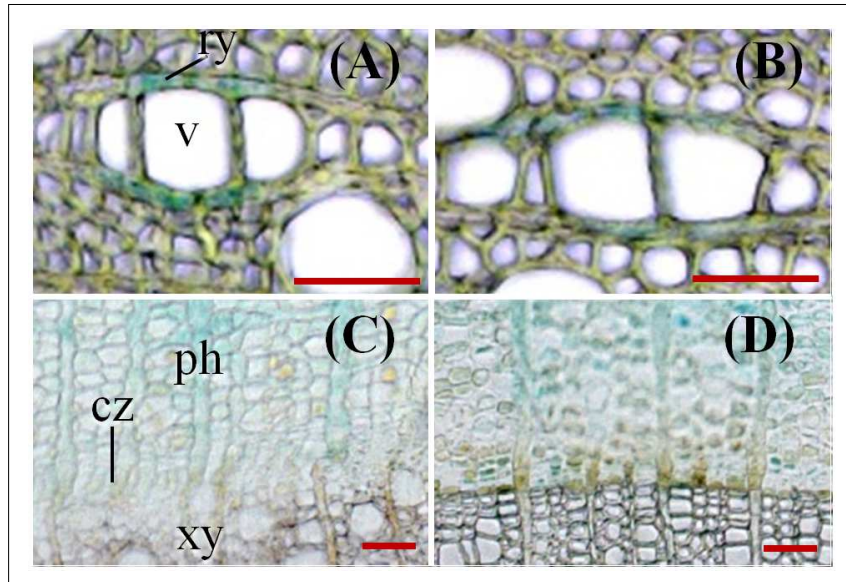

FIGURE 6 | ARR5::GUS activity observed in the xylem rays $(A, B)$ and in cambium (C,D) at the stem bottom of Populus $x$ canescens in the growth phase and during dormancy. $(\mathbf{A}, \mathbf{C})$ represent samples from growth phase and (B,D) represent samples during dormancy of line 32. The following abbreviations were used: ry, ray cell; v, vessel; ph, phloem; cz, cambial zone; and $x y$, xylem. Scale bar $=50 \mu \mathrm{m}$.

time. In winter, ARR5::GUS activity was present mainly in the outer pith region, the perimedullary zone (Figure $\mathbf{8 A}$ ), whereas in the stem top sections from the growth phase most of the ARR5::GUS activity was localized in the center of the pith. In the stem middle, anatomy and the pattern of ARR5::GUS activity were similar to that at the stem bottom (Figures $\mathbf{8 B}, \mathbf{C}$ ). The ARR5::GUS activity extended across the whole cortex region of the bark and therefore, was stronger than in summer in this tissue (Figures 8B,C). Similar as in summer, the staining was pronounced in cell files that were connected with xylem rays (Figures $\mathbf{8 B}, \mathbf{C}$ ). ARR5::GUS activity was also localized in the cambial zone at the stem bottom during dormancy with a stronger signal than that detected in summer (Figure 6D).

Similar as in summer, the ray cells adjacent to vessels showed ARR5::GUS activity (Figure 6B), but the stain was less pronounced than in summer (Figure 6A). The ARR5::GUS activity in distinct locations of the xylem rays was only present at the stem bottom.

\section{Tissue Specific Expression Pattern of PtRR Type-A Genes}

The expression of genes belonging to the type-A RR family in poplar was analyzed in different tissues employing microarray data (Figure 9). Each of the 11 genes identified in poplar (Ramírez-Carvajal et al., 2008, cf. Table 1) had a probe set on the microarrays and therefore could be included here. There was no clustering of the PtRR transcriptional pattern according to tissues (not shown), but all tissues showed an expression of all $P t R R$ type-A genes (Figure 9). The PtRR transcriptional pattern clearly clustered the genes in two categories, one comprising genes with low expression (PtRR8, 9, and 11) and the other with genes that showed variable expression across the tissues and season (PtRR1, 2, 3, 4, 5, 6, 7, and 10). PtRR10, the ortholog of $A R R 5$, was expressed in all tissues under study, especially in the phloem and elongation zone in the growth phase (Figure 9), thus supporting consistency between PtRR10 expression and our reporter lines. In the fine roots from the growth phase, mainly PtRR10 was expressed while in the young roots PtRR5 was also expressed. PtRR5, 3, and 1 showed strong expression in the phloem during the growth phase. In the cambium tissues during summer, PtRR10 and 5 were mainly expressed. In developing xylem, during growth phase, PtRR10, 5, and 6 showed strong expression. PtRR5 showed a strong expression in the developing xylem in summer followed by PtRR10 and 4. In the summer rays, PtRR10 and 1 showed strong expression. PtRR7 was also expressed in summer ray cells. But in winter rays, only PtRR1 showed strong expression. In the elongation zone of the stem, during the growth phase, $P t R R 10,5,3,6,1$, and 5 were strongly expressed. In the shoot apex only PtRR10 was strongly expressed.

\section{DISCUSSION}

\section{The ARR5::GUS Construct Is Functional in Poplar}

Many of the biological and developmental phenomena shared by herbaceous and woody plants are regulated by the same molecular mechanism. Besides having the same cytokinin signal transduction components, the type- $A R R$ gene family found in Arabidopsis and poplar is well conserved in these two plant species (Immanen et al., 2013) with the highest similarity between PtRR10 and ARR5 (Ramírez-Carvajal et al., 2008; Immanen et al., 2013). Here, we show that the ARR5::GUS reporter construct was functional in poplar because it was inducible by the cytokinin analogs, thidiazuron and BAP and not by adenine, an inactive cytokinin analog. Thus, ARR5::GUS transformed poplar lines record the distribution of active cytokinins selectively. However, quantification of the signal is not possible because of the unknown turnover of GUS and the produced indigo dye.

Normal growth of the transgenic poplars indicated that there was no significant non-target effect of the biotechnological modification on plant performance. However, in one of the three reporter lines, ARR5::GUS construct was apparently silenced during long-term growth under ambient conditions. Silencing is not uncommon in transgenic plants and can have a number of different reasons (Stam et al., 1997; Fagard and Vaucheret, 2000). The synthetic promoter construct TCS::GFP for monitoring cytokinin in Arabidopsis was also subjected to silencing (Zürcher et al., 2013). Here, the two active reporter lines showed similar patterns of the ARR5::GUS activity in those tissues that also showed PtRR10 expression, thus, supporting that they confidently recorded cytokinin activity.

\section{The Localization of ARR5::GUS Identifies Novel Cytokinin-Active Cell Types in Poplar}

In the growing phase, the main tissues with strong ARR5::GUS activity included the apical bud base, the root tips, pith in stem elongation zone, and bark in the stem middle and bottom. The localization of active cytokinins in the apical bud base and in 


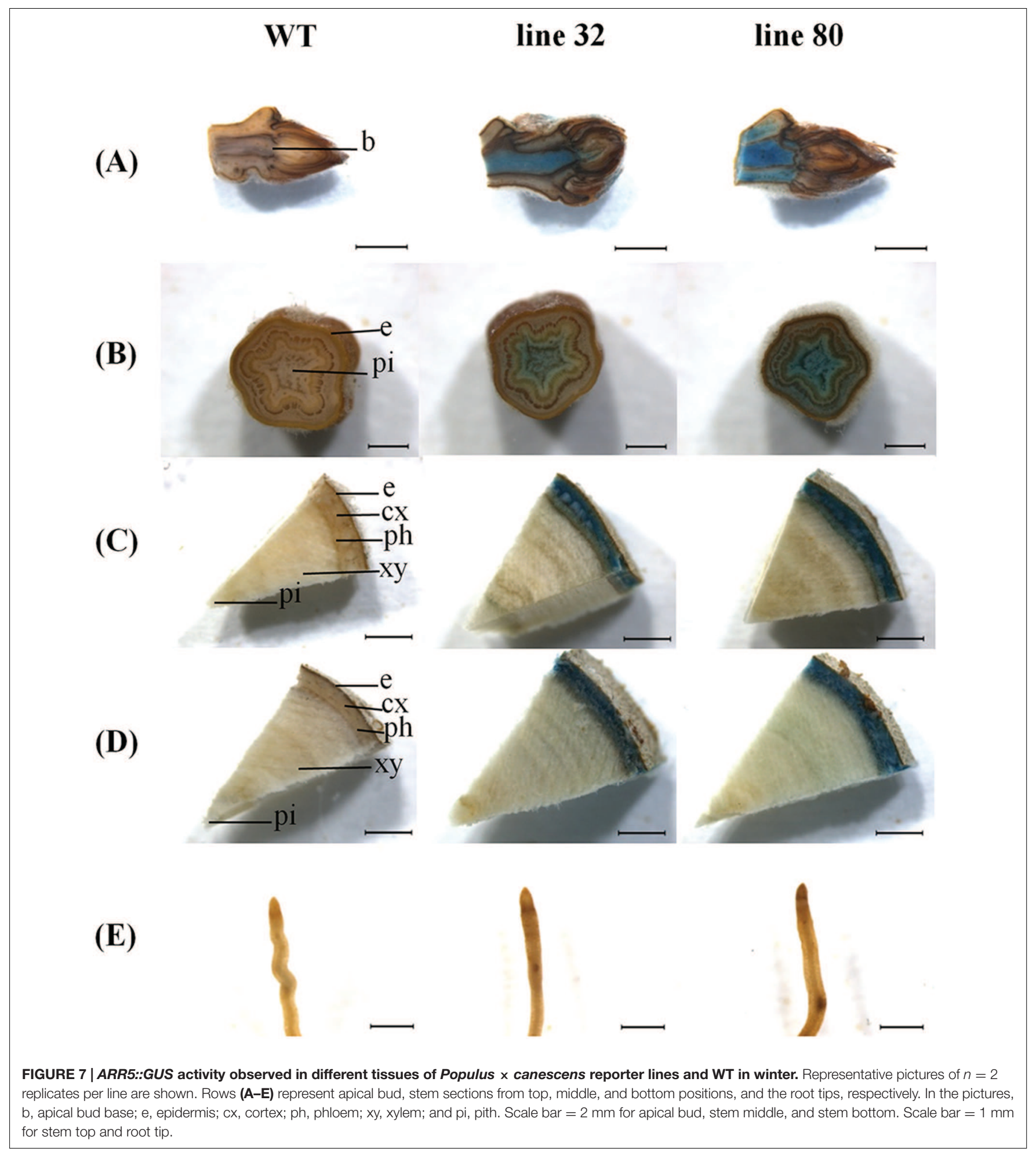

root tips shows strong similarity to that observed in ARR5::GUS expressing Arabidopsis seedlings (D'Agostino et al., 2000). In Arabidopsis seedlings, the primary and lateral root tips showed strong ARR5::GUS activity in the root cap region as well as in the cell division region and elongation zone with a gradual decrease toward the direction of the shoot apex (D'Agostino et al., 2000). This staining pattern was also evident in the growing season in poplar root tips in our study. Aloni et al. (2004) reported that the ARR5::GUS signal in Arabidopsis roots was produced in the statocytes. 


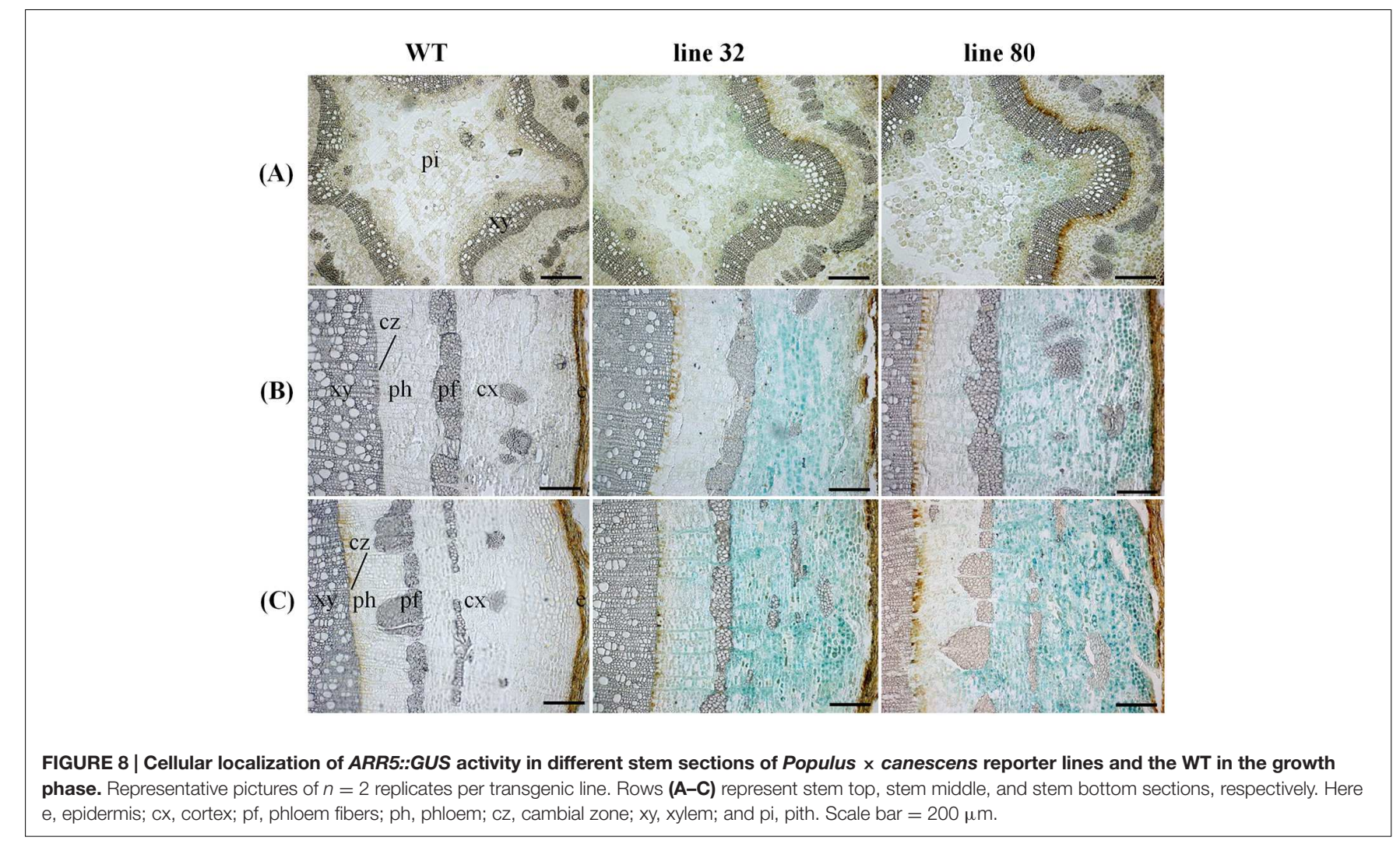

FIGURE 8 | Cellular localization of ARR5::GUS activity in different stem sections of Populus $\mathrm{x}$ canescens reporter lines and the WT in the growth e, epidermis; cx, cortex; pf, phloem fibers; ph, phloem; cz, cambial zone; xy, xylem; and pi, pith. Scale bar $=200 \mu \mathrm{m}$.
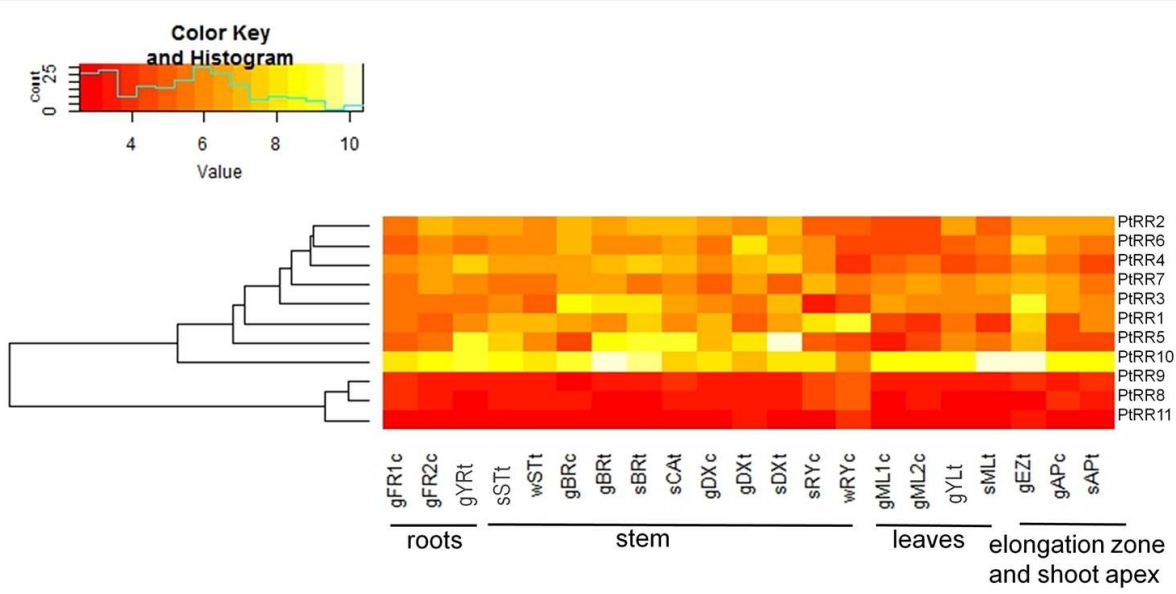

FIGURE 9 | Tissue-specific expression pattern of poplar genes belonging to the two component response regulator (PtRR) type-A gene family of cytokinin signaling pathway. The following abbreviations were used: FR, fine roots; YR, young roots; ST, stem bottom; BR, bark; CA, cambium; DX, developing xylem; RY, ray cells; ML, mature leaves; YL, young leaves; EZ, elongation zone; AP, shoot apex. The prefixes g, growing plants in controlled conditions; s, summer; and $w$, winter. The suffix c, tissues from $P . \times$ canescens and t, tissues from $P$. trichocarpa. The numbers 1 and 2 represent two different experiments. PtRR9 has no assigned ARR name in Arabidopsis (see Table 1)

In the stem top, the observation of ARR5::GUS activity in the pith was unexpected, but similarly Teichmann et al. (2008) also had found auxin activity in this tissue. This finding suggests that the pith may have an important function for the hormone supply in the young stem, where the vascular system is not yet fully differentiated. Active cytokinins were also detected in the cambial zone of poplar, in agreement with studies showing that cytokinins are important regulators of cambial activity in growing poplars (Matsumoto-Kitano et al., 2008; Nieminen et al., 2008).

The presence of active cytokinins in the xylem ray cells, which was detected here, has not been reported so far, but was underpinned by high expression of poplar PtRR10, PtRR1, and $P t R R 7$ in this cell type. A noteworthy finding was that 
the ARR5::GUS activity in the ray cells was seen only in parts associated with vessels. The biological significance of high cytokinin activity close to the vessels is unknown. However, root-derived cytokinin that are transported with the xylem sap through the vessel, are likely to be supplied by this route to the rays.

The ARR5::GUS staining pattern observed in the bark cortical cells, primary rays and in the cambium support previous studies reporting that cytokinins are necessary for determining vascular cell identities (Mähönen et al., 2000; Hutchison et al., 2006; Yokoyama et al., 2007; Argyros et al., 2008) and stimulate growth (Werner et al., 2003). The positional pattern of active cytokinin found here agrees with strong expression of the type-ARR genes PtRR3, PtRR5, and PtRR10) in the phloem of greenhouse grown P. trichocarpa (Ramírez-Carvajal et al., 2008). Furthermore, we found strong expression of PtRR10, PtRR5, $P t R R 3$, and PtRR1 in bark tissues. In the cambium PtRR10 and PtRR5 were highly expressed indicating responsiveness to cytokinins.

The reporter lines generally show expected localization pattern, but an exception was also noted. Although PtRR10 was expressed in mature leaves, no ARR5::GUS activity was found in these tissues. One possibility is that $P t R R 10$ transcription is regulated by further signals to which $A R R 5$ is not responsive or the ARR5::GUS reporter construct is insensitive to cytokinins in fully expanded leaves in summer. Similar cases have been reported for poplar auxin reporter lines transformed with GH3::GUS (Teichmann et al., 2008) and DR5::GUS (Chen et al., 2013), where no activity of these constructs was noted in the cambium, a tissue in which an auxin maximum is expected. However, in our study ARR5::GUS activity was detected in the leaf primordia, where cytokinin levels determine leaf size (Holst et al., 2011) A comparison of ARR5::GUS activity along the stem with that of auxin reporter lines (GH3::GUS, DR5::GUS, Teichmann et al., 2008; Chen et al., 2013) shows overlap of the hormone activities in the elongation zone, but contrasting intensities in the bark. In ARR5::GUS poplars, the staining in bark was stronger toward the stem base, whereas that of auxin reporter lines decreased toward the base. These observations indicate that the phytohormone reporter lines also truly reflect the hormone gradients installed by the opposite apical production sites in roots for cytokinins and in the stem for auxin and the inverse transport pattern of these phytohormones along the stem (Jones and Ljung, 2011).

\section{Cytokinin Activity Is Subject to Seasonal Fluctuations in Distinct Tissues}

Seasonal fluctuation of cytokinin activity was most notable in the root tips, the major site of cytokinin synthesis (Aloni et al., 2004, 2005). The absence of ARR5::GUS activity in the root tips during dormancy together with a strong presence of ARR5::GUS activity in the apical bud base, in the pith, and in the bark suggests that the active cytokinins in these shoot tissues may be shootderived rather than root-derived. Cytokinins from different production sites have been distinguished by their chemical composition. Root-derived cytokinins are mainly of the transzeatin (tZ) type (Aloni et al., 2005), whereas phloem-transported isopentenyladenine (iP) type cytokinins are considered to be shoot-derived (Bishopp et al., 2011). In winter, the concentration of $\mathrm{tZ}$ is low in the xylem sap of willows, probably because of their decreased root production (Alvim et al., 1976), which corresponds to the lacking ARR5::GUS signal in our study. At the start of dormancy very high levels of the iP type are present in the phloem sap of 14 different tree species (Weiler and Ziegler, 1981). The studies with excised twigs of Populus $\times$ robusta and rootless almond shoots also confirm the presence of cytokinin after chilling (Hewett and Wareing, 1973; Van Staden and Dimalla, 1981). Increased cytokinin levels of the bark and in buds before the bud burst were further reported in artificially chilled, excised apple shoots (Cook et al., 2001). All these studies suggested that shoot derived cytokinins play a role in dormancy and the following bud burst in spring. The source of these cytokinins could be de novo biosynthesis or conversion of storage forms to their active forms (Skene, 1972; Kannangara and Booth, 1974; Van Staden and Brown, 1978; Van Staden, 1979; Van Staden and Dimalla, 1981). Collectively, these studies show that cytokinins are present in the dormant phase and together with our results on ARR5::GUS activity, it is clear that they are active in distinct cell types such as cortical and ray cells in the bark, pith, and ray cells next to vessels and in the shoot apex. In the cambial zone, a strong staining was also detected during dormancy. This observation may suggest a role of cytokinins in cambial cell maintenance in winter.

\section{CONCLUSION}

Employing an ARR5::GUS reporter, we monitored seasonal differences and similarities of cytokinin activity at the tissue and cellular level in poplar. Since cytokinins increase the sensitivity of the cambium to the auxin signal, they are important regulators of wood quantity and quality (Aloni, 1991, 2001). Therefore, the reporter lines can be used to investigate the involvement of cytokinins in mediating growth constraints and growthpromoting treatments for vascular development and cell type identities in the future. Thereby, these poplars may become an important tool to enhance our understanding of woody biomass production.

\section{AUTHOR CONTRIBUTIONS}

SP conducted field and laboratory experiments, analyzed data, and wrote the manuscript. HW supervised experiments, analyzed data, and commented on manuscript. DJ analyzed bioinformatic data and commented on the manuscript. TT constructed the vectors, characterized transformants, and commented on the manuscript. RH transformed plants, tested the transformants, and commented on the manuscript. AP designed the experiments, analyzed data, and wrote the manuscript. All authors contributed to the final version of the manuscript. 


\section{FUNDING}

We are grateful to the German Science Foundation for financial support for the generation of the poplar lines in the frame of Poplar Research Group Germany (PRG, FOR546, Po362-12, Po362-13). SP thanks the European Commission for the Ph.D. scholarship in the Erasmus Mundus (India4EU II) program. The outdoor study was conducted in the frame of WATBIO (Development of improved perennial non-food biomass and bioproduct crops for water-stressed environments) which is a collaborative research project funded from the European Union's Seventh Programme for research, technological development and demonstration under grant agreement No. 311929. The publication fund of the University of Göttingen and the Deutsche

\section{REFERENCES}

Aloni, R. (1991). "Wood formation in deciduous hardwood trees," in Physiology of Trees, ed. A. S. Raghavendra (New York, NY: Wiley), 175-197.

Aloni, R. (2001). Foliar and axial aspects of vascular differentiation: hypotheses and evidence. J. Plant Growth Regul. 20, 22-34. doi: 10.1007/s003440010001

Aloni, R., Langhans, M., Aloni, E., Dreieicher, E., and Ullrich, C. I. (2005). Root-synthesized cytokinin in Arabidopsis is distributed in the shoot by the transpiration stream. J. Exp. Bot. 56, 1535-1544. doi: 10.1093/jxb/eri148

Aloni, R., Langhans, M., Aloni, E., and Ullrich, C. I. (2004). Role of cytokinin in the regulation of root gravitropism. Planta 220, 177-182. doi: 10.1007/s00425-0041381-8

Alvim, R., Hewett, E. W., and Saunders, P. F. (1976). Seasonal variation in the hormone content of Willow: I. changes in abscisic acid content and cytokinin activity in the xylem Sap 1. Plant physiol. 57, 474-476. doi: 10.1104/pp. 57.4.474

Argyros, R. D., Mathews, D. E., Chiang, Y.-H., Palmer, C. M., Thibault, D. M., Etheridge, N., et al. (2008). Type B response regulators of Arabidopsis play key roles in cytokinin signaling and plant development. The Plant Cell Online 20, 2102-2116. doi: 10.1105/tpc.108.059584

Bai, H., Euring, D., Volmer, K., Janz, D., and Polle, A. (2013). The nitrate transporter (NRT) gene family in poplar. PLoS ONE 8:e72126. doi: 10.1371/journal.pone.0072126

Bishopp, A., Help, H., El-Showk, S., Weijers, D., Scheres, B., Friml, J., et al. (2011). A mutually inhibitory interaction between auxin and cytokinin specifies vascular pattern in roots. Curr. Biol. 21, 917-926. doi: 10.1016/j.cub.2011. 04.017

Chen, Y., Yordanov, Y. S., Ma, C., Strauss, S., and Busov, V. B. (2013). DR5 as a reporter system to study auxin response in Populus. Plant Cell Rep. 32, 453-463. doi: 10.1007/s00299-012-1378-x

Cook, N. C., Bellstedt, D. U., and Jacobs, G. (2001). Endogenous cytokinin distribution patterns at budburst in Granny Smith and Braeburn apple shoots in relation to bud growth. Sci. Hortic. 87, 53-63. doi: 10.1016/S03044238(00)00161-8

D'Agostino, I. B., Deruère, J., and Kieber, J. J. (2000). Characterization of the response of the Arabidopsis response regulator gene family to cytokinin. Plant Physiol. 124, 1706-1717. doi: 10.1104/pp.124.4.1706

Dieleman, J. A., Verstappen, F. W. A., Nicander, B., Kuiper, D., Tillberg, E., and Tromp, J. (1997). Cytokinins in Rosa hybrida in relation to bud break. Physiol. Plant. 99, 456-464. doi: 10.1111/j.1399-3054.1997. tb00560.x

Euring, D., Bai, H., Janz, D., and Polle, A. (2014). Nitrogen-driven stem elongation in poplar is linked with wood modification and gene clusters for stress, photosynthesis and cell wall formation. BMC Plant Biol. 14:391. doi: 10.1186/s12870-014-0391-3

Fagard, M., and Vaucheret, H. (2000). (Trans) gene silencing in plants: how many mechanisms? Annu. Rev. Plant Physiol. Plant Mol. Biol. 51, 167-194. doi: 10.1146/annurev.arplant.51.1.167
Forschungsgemeinschaft supported open access publication of this article. This publication reflects the views only of the authors, and the European commission cannot be held responsible for any use which may be made of the information contained therein.

\section{ACKNOWLEDGMENTS}

We thank Merle Fastenrath, Marion Kay, Christine Kettner, Marianne Smiatacz, Giesbert Langer, and Monika Franke-Klein for maintenance of the stock cultures and for their excellent technical support of the outdoor study and Mareike Kavka for introducing array analyses using R to SP.

Gautier, L., Cope, L., Bolstad, B. M., and Irizarry, R. A. (2004). Affy-analysis of Affymetrix GeneChip data at the probe level. Bioinformatics 20, 307-315. doi: 10.1093/bioinformatics/btg405

Goodstein, D. M., Shu, S., Howson, R., Neupane, R., Hayes, R. D., Fazo, J., et al. (2012). Phytozome: a comparative platform for green plant genomics. Nucleic Acids Res. 40, D1178-D1186. doi: 10.1093/nar/gkr944

He, J., Li, H., Luo, J., Ma, C., Li, S., Qu, L., et al. (2013). A transcriptomic network underlies microstructural and physiological responses to cadmium in Populus $\times$ canescens. Plant Physiol. 162, 424-439. doi: 10.1104/pp.113.215681

Hewett, E. W., and Wareing, P. F. (1973). Cytokinins in Populus $\times$ robusta Schneid: a complex in leaves. Planta 112, 225-233. doi: 10.1007/BF00385326

Hirose, N., Takei, K., Kuroha, T., Kamada-Nobusada, T., Hayashi, H., and Sakakibara, H. (2008). Regulation of cytokinin biosynthesis, compartmentalization and translocation. J. Exp. Bot. 59, 75-83. doi: $10.1093 / \mathrm{jxb} / \mathrm{erm} 157$

Holst, K., Schmülling, T., and Werner, T. (2011). Enhanced cytokinin degradation in leaf primordia of transgenic Arabidopsis plants reduces leaf size and shoot organ primordia formation. J. Plant Physiol. 168, 1328-1334. doi: 10.1016/j.jplph.2011.03.003

Hutchison, C. E., Li, J., Argueso, C., Gonzalez, M., Lee, E., Lewis, M. W., et al. (2006). The Arabidopsis histidine phosphotransfer proteins are redundant positive regulators of cytokinin signaling. Plant Cell Online 18, 3073-3087. doi: $10.1105 /$ tpc. 106.045674

Hwang, I., Sheen, J., and Müller, B. (2012). Cytokinin signaling networks. Annu. Rev. Plant Biol. 63, 353-380. doi: 10.1146/annurev-arplant-042811-105503

Immanen, J., Nieminen, K., Silva, H. D., Rojas, F. R., Meisel, L. A., Silva, H., et al. (2013). Characterization of cytokinin signaling and homeostasis gene families in two hardwood tree species: Populus trichocarpa and Prunus persica. BMC Genomics 14:885. doi: 10.1186/1471-2164-14-885

Janz, D., Behnke, K., Schnitzler, J.-P., Kanawati, B., Schmitt-Kopplin, P., and Polle, A. (2010). Pathway analysis of the transcriptome and metabolome of salt sensitive and tolerant poplar species reveals evolutionary adaption of stress tolerance mechanisms. BMC Plant Biol. 10:150. doi: 10.1186/1471-2229-10-150

Janz, D., Lautner, S., Wildhagen, H., Behnke, K., Schnitzler, J.-P., Rennenberg, H., et al. (2012). Salt stress induces the formation of a novel type of pressure wood in two Populus species. New Phytol. 194, 129-141. doi: 10.1111/j.14698137.2011.03975.x

Jefferson, R. A., Kavanagh, T. A., and Bevan, M. W. (1987). GUS fusions: $\beta$-Glucuronidase as a sensitive and versatile gene fusion marker in higher plants. ЕМВО J. 6, 3901-3907.

Jones, B., and Ljung, K. (2011). Auxin and cytokinin regulate each other's levels via a metabolic feedback loop. Plant Signal. Behav. 6, 901-904. doi: 10.4161/psb.6.6.15323

Kamada-Nobusada, T., and Sakakibara, H. (2009). Molecular basis for cytokinin biosynthesis. Phytochemistry 70, 444-449. doi: 10.1016/j.phytochem. 2009.02.007

Kannangara, T., and Booth, A. (1974). Diffusible cytokinins in shoot apices of Dahlia variabilis. J. Exp. Bot. 25, 459-467. doi: 10.1093/jxb/25.2.459 
Kauffmann, A., Rayner, T. F., Parkinson, H., Kapushesky, M., Lukk, M., Brazma, A., et al. (2009). Importing ARRAYEXPRESS datasets into R/ bioconductor. Bioinformatics 25, 2092-2094. doi: 10.1093/bioinformatics/btp354

Kieber, J. J., and Schaller, G. E. (2014). Cytokinins. Arabidopsis Book 12:e0168. doi: $10.1199 /$ tab.0168

Ko, J.-H., Kim, H.-T., Hwang, I., and Han, K.-H. (2012). Tissue-type-specific transcriptome analysis identifies developing xylem-specific promoters in poplar: xylem-specificutility promoters in poplar. Plant Biotechnol. J. 10, 587596. doi: 10.1111/j.1467-7652.2012.00690.x

Kolesnikov, N., Hastings, E., Keays, M., Melnichuk, O., Tang, Y. A., Williams, E., et al. (2015). ArrayExpress update-simplifying data submissions. Nucleic Acids Res. 43, D1113-D1116. doi: 10.1093/nar/gku1057

Larisch, C., Dittrich, M., Wildhagen, H., Lautner, S., Fromm, J., Polle, A., et al. (2012). Poplar wood rays are involved in seasonal remodeling of tree physiology. Plant Physiol. 160, 1515-1529. doi: 10.1104/pp.112.202291

Leple, J. C., Brasileiro, A. C. M., Michel, M. F., Delmotte, F., and Jouanin, L. (1992). Transgenic poplars: expression of chimeric genes using four different constructs. Plant Cell Rep. 11, 137-141. doi: 10.1007/BF00232166

Luo, Z.-B., Janz, D., Jiang, X., Gobel, C., Wildhagen, H., Tan, Y., et al. (2009). Upgrading root physiology for stress tolerance by ectomycorrhizas: insights from metabolite and transcriptional profiling into reprogramming for stress anticipation. Plant Physiol. 151, 1902-1917. doi: 10.1104/pp.109.143735

Mähönen, A. P., Bonke, M., Kauppinen, L., Riikonen, M., Benfey, P. N., and Helariutta, Y. (2000). A novel two-component hybrid molecule regulates vascular morphogenesis of the Arabidopsis root. Genes Dev. 14, 2938-2943. doi: 10.1101/gad.189200

Matsumoto-Kitano, M., Kusumoto, T., Tarkowski, P., Kinoshita-Tsujimura, K., Václavíková, K., Miyawaki, K., et al. (2008). Cytokinins are central regulators of cambial activity. Proc. Natl. Acad. Sci. U.S.A. 105, 20027-20031. doi: 10.1073/pnas. 0805619105

Miyawaki, K., Matsumoto-Kitano, M., and Kakimoto, T. (2004). Expression of cytokinin biosynthetic isopentenyltransferase genes in Arabidopsis: tissue specificity and regulation by auxin, cytokinin, and nitrate. Plant J. 37, 128-138. doi: 10.1046/j.1365-313X.2003.01945.x

Mizuno, T. (2005). Two-component phosphorelay signal transduction systems in plants: from hormone responses to circadian rhythms. Biosci. Biotechnol. Biochem. 69, 2263-2276. doi: 10.1271/bbb.69.2263

Mok, D. W., and Mok, M. C. (2001). Cytokinin metabolism and action. Annu. Rev. Plant Physiol. Plant Mol. Biol. 52, 89-118. doi: 10.1146/annurev.arplant.52.1.89

Müller, A., Volmer, K., Mishra-Knyrim, M., and Polle, A. (2013). Growing poplars for research with and without mycorrhizas. Front. Plant Sci. 4:332. doi: 10.3389/fpls.2013.00332

Nieminen, K., Immanen, J., Laxell, M., Kauppinen, L., Tarkowski, P., Dolezal, K., et al. (2008). Cytokinin signaling regulates cambial development in poplar. Proc. Natl. Acad. Sci. U.S.A. 105, 20032-20037. doi: 10.1073/pnas.0805617106

Pils, B., and Heyl, A. (2009). Unraveling the evolution of cytokinin signaling. Plant Physiol. 151, 782-791. doi: 10.1104/pp.109.139188

R Core Team (2014). R: A Language and Environment for Statistical Computing. Vienna: R foundation for statistical computing. Available at: http://www.R-proj ect.org/

Ramírez-Carvajal, G. A., Morse, A. M., and Davis, J. M. (2008). Transcript profiles of the cytokinin response regulator gene family in Populus imply diverse roles in plant development. New Phytol. 177, 77-89. doi: 10.1111/j.14698137.2007.02240.x

Romanov, G. A., Lomin, S. N., and Schmulling, T. (2006). Biochemical characteristics and ligand-binding properties of Arabidopsis cytokinin receptor AHK3 compared to CRE1/AHK4 as revealed by a direct binding assay. J. Exp. Bot. 57, 4051-4058. doi: 10.1093/jxb/erl179

Sakakibara, H. (2006). Cytokinins: activity, biosynthesis, and translocation. Annu. Rev. Plant Biol. 57, 431-449. doi: 10.1146/annurev.arplant.57.032905.105231

Schaller, G. E., Kieber, J. J., and Shiu, S.-H. (2008). Two-component signaling elements and histidyl-aspartyl phosphorelays. Arabidopsis Book 6:e0112. doi: $10.1199 /$ tab.0112

Skene, K. G. (1972). Cytokinins in the xylem sap of grape vine canes: changes in activity during cold-storage. Planta 104, 89-92. doi: 10.1007/BF00387686

Stam, M., Mol, J. N., and Kooter, J. M. (1997). The silence of genes in transgenic plants. Ann. Bot. 79, 3-12. doi: 10.1006/anbo.1996.0295
Tanaka, M., Takei, K., Kojima, M., Sakakibara, H., and Mori, H. (2006). Auxin controls local cytokinin biosynthesis in the nodal stem in apical dominance. Plant J. 45, 1028-1036. doi: 10.1111/j.1365-313X.2006.02656.x

Taniguchi, M., Kiba, T., Sakakibara, H., Ueguchi, C., Mizuno, T., and Sugiyama, T. (1998). Expression of Arabidopsis response regulator homologs is induced by cytokinins and nitrate. FEBS Lett. 429, 259-262. doi: 10.1016/S00145793(98)00611-5

Teichmann, T., Bolu-Arianto, W. H., Olbrich, A., Langenfeld-Heyser, R., Göbel, C., Grzeganek, P., et al. (2008). GH3::GUS reflects cell-specific developmental patterns and stress-induced changes in wood anatomy in the poplar stem. Tree Physiol. 28, 1305-1315. doi: 10.1093/treephys/28.9.1305

Tromp, J., and Ovaa, J. C. (1990). Seasonal changes in the cytokinin composition of xylem sap of Apple. J. Plant Physiol. 136, 606-610. doi: 10.1016/S01761617(11)80221-X

Tsai, C. J., Ranjan, P., DiFazio, S. P., Tuskan, G. A., and Johnson, V. (2011). “Poplar genome microarrays," in Genetics, Genomics and Breeding of Poplars, eds C. P. Joshi, S. P. DiFazio, and C. Kole (Enfield: Science Publishers), 112-127.

Van Staden, J. (1979). Changes in the endogenous cytokinin levels of excised buds of Salix babylonica L., cultured aseptically. Bot. Gaz. 140, 138-141. doi: $10.1086 / 337069$

Van Staden, J., and Brown, N. A. C. (1978). Changes in the endogenous cytokinins of bark and buds of Salix babylonica as a result of stem girdling. Physiol. Plant. 43, 148-153. doi: 10.1111/j.1399-3054.1978.tb01583.x

Van Staden, J., and Dimalla, G. G. (1981). The production and utilisation of cytokinins in rootless, dormant Almond shoots maintained at low temperature. Z. Pflanzenphysiol. 103, 121-129. doi: 10.1016/S0044-328X(81)8 0141-9

Warnes, G. R., Bolker, B., Bonebakker, L., Gentleman, R., Liaw, W. H. A., Lumley, T., et al. (2012). Gplots: Various R Programming Tools for Plotting Data. Available at: http://CRAN.R-project.org/package $=$ gplots

Wei, H., Yordanov, Y. S., Georgieva, T., Li, X., and Busov, V. (2013). Nitrogen deprivation promotes Populus root growth through global transcriptome reprogramming and activation of hierarchical genetic networks. New Phytol. 200, 483-497. doi: 10.1111/nph.12375

Weiler, E. W., and Ziegler, H. (1981). Determination of phytohormones in phloem exudate from tree species by radioimmunoassay. Planta 152, 168-170. doi: $10.1007 /$ BF00391189

Werner, T., Motyka, V., Laucou, V., Smets, R., Van Onckelen, H., and Schmülling, T. (2003). Cytokinin-deficient transgenic Arabidopsis plants show multiple developmental alterations indicating opposite functions of cytokinins in the regulation of shoot and root meristem activity. Plant Cell Online 15, 2532-2550. doi: 10.1105/tpc.014928

Yokoyama, A., Yamashino, T., Amano, Y.-I., Tajima, Y., Imamura, A., Sakakibara, H., et al. (2007). Type-B ARR transcription factors, ARR10 and ARR12, are implicated in cytokinin-mediated regulation of protoxylem differentiation in roots of Arabidopsis thaliana. Plant Cell Physiol. 48, 84-96. doi: $10.1093 / \mathrm{pcp} / \mathrm{pcl} 040$

Yordanov, Y. S., Ma, C., Strauss, S. H., and Busov, V. B. (2014). EARLY BUD-BREAK 1 (EBB1) is a regulator of release from seasonal dormancy in poplar trees. Proc. Natl. Acad. Sci. U.S.A. 111, 10001-10006. doi: 10.1073/pnas.1405621111

Zürcher, E., Tavor-Deslex, D., Lituiev, D., Enkerli, K., Tarr, P. T., and Müller, B. (2013). A robust and sensitive synthetic sensor to monitor the transcriptional output of the cytokinin signaling network in planta. Plant Physiol. 161, 10661075. doi: $10.1104 /$ pp. 112.211763

Conflict of Interest Statement: The authors declare that the research was conducted in the absence of any commercial or financial relationships that could be construed as a potential conflict of interest.

Copyright (๑) 2016 Paul, Wildhagen, Janz, Teichmann, Hänsch and Polle. This is an open-access article distributed under the terms of the Creative Commons Attribution License (CC BY). The use, distribution or reproduction in other forums is permitted, provided the original author(s) or licensor are credited and that the original publication in this journal is cited, in accordance with accepted academic practice. No use, distribution or reproduction is permitted which does not comply with these terms. 